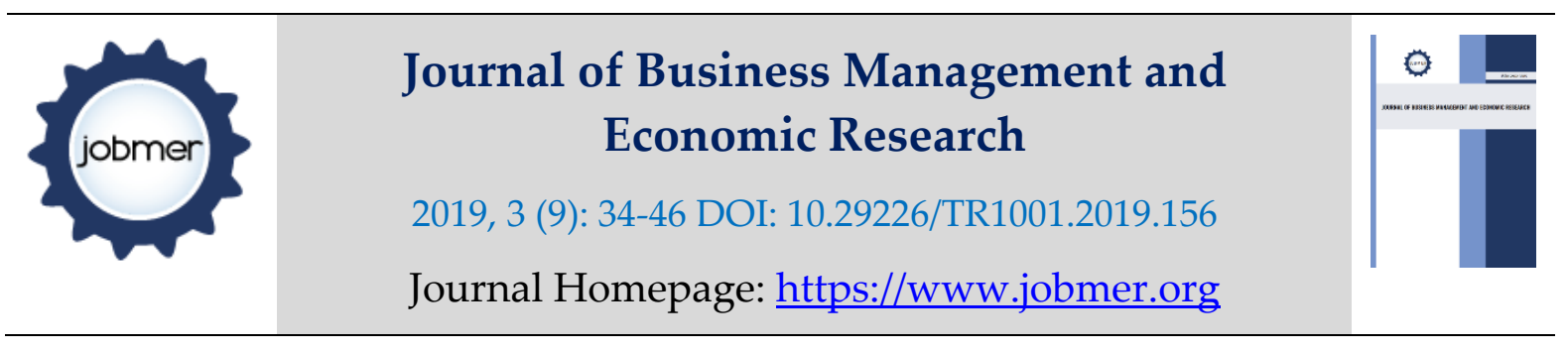

\title{
Influence of Logistic Service Reliability Capability on Firm Performance in Kenya
}

\author{
Edwin Kimitei \\ Department of Marketing \& Logistics, Moi University, Kenya \\ Corresponding author's email: edukimitei@gmail.com
}

\section{Charles Lagat}

Department of Marketing \& Logistics, Moi University, Kenya

\section{Joel Chepkwony}

Department of Marketing \& Logistics, Moi University, Kenya

\section{Jane Sang}

Department of Management Science, Moi University, Kenya

\begin{abstract}
Firms integrate logistic capabilities in their operations to improve performance, which is advocated by the resource-based view theory. Many forms of logistic capabilities exist, but the most widely used is the logistic service reliability capability. There are numerous attributes of logistic service reliability capabilities used by firms which could potentially affect the effectiveness of the logistic service reliability capabilities on firm performance. Therefore, this study determined the influence of the attributes of logistic service reliability capability on firm performance of manufacturing firms in Kenya. The independent variables were firm reviews, client services, research for firm performance, reverse logistics operations, logistics service differentiation and logistics solutions. Using an explanatory research design, the study targeted 750 manufacturing firms registered under Kenya Association of Manufacturers from where a sample size of 442 firms was selected. The samples were selected using stratified and simple random sampling approaches. The findings of the study established that there was a positive significant influence of the attributes of logistic service reliability on firm performance (R-squared $=0.6421, P<0.05$ ). Therefore, whenever firms aim at optimizing logistic service reliability capability, the firms must pay more attention to each attribute of the logistic service reliability capability. Therefore, exploring avenues of improving each attribute of logistic service reliability capability of firms may eventually improve the overall performance of the manufacturing firms.
\end{abstract}

Keywords: Firm Performance; Logistic Capabilities; Logistic Service Reliability Capability; Manufacturing firms, Kenya 
Journal of Business Management and Economic Research (JOBMER), vol.3, issue.9, pp.34-46

\section{Introduction}

Firm performance are characterized in terms of effectiveness, efficiency, relevance, and financial practicality (Arena et al., 2015). Effectiveness, measures the degree to which the organization is successful in achieving its internal strategy while efficiency refer to how well the organization utilizes its resources in pursuit of its goals, relevance measure to provide information on the degree to which stakeholders believe that the organization is relevant in meeting its needs. There are several measures in firms indicating the performance. Among these, financial outcomes such profit margins, return on assets (ROA), return on investment (ROI), shareholder returns etc. are key considerations (Kharatyan et al., 2016). Emphasis has also been laid on an assortment of non financial aspects such as market share, customer service, social responsibility, employee stewardship etc (Kristjansdottir et al., 2016; Torres et al., 2018; Owens et al., 2019). Strategies that ensure optimal firm performance often strive to couple links between financial and non financial measure in the firm (Ibrahim \& Lloyd, 2011; Chiang \& Birtch, 2012). Firms employ several strategies to improve their overall performance, including emphasis on logistic capabilities of the firms (Liu \& Luo, 2012).

Logistic capabilities include the firm's resources (including assets, competencies, processes, firm attributes, information, etc) that permit them to implement plans that improve business efficiency and effectiveness (Najafizadeh \& Kazemi, 2019). Firms engage logistic capabilities in supporting production, building firm's effectiveness, and facilitating profitability in the business environment (Durst \& Evangelista, 2018). The capabilities are unique to each organization and may therefore differentially influence the inclusive performance. This include coordinating assets, competencies, organizational processes, information, knowledge etc (Schönsleben, 2018; Zijm et al., 2019). Many firms prioritize to improve their logistics capabilities by giving more attention to logistic service reliability capability.

Logistics service reliability capability form fundamental part of any supply chain management involving designing, implementation, and regulation of forward, and backward flow effectively and efficiently as well as storage of goods, services, and related information (Franceschini \& Rafele, 2000; Chapman et al., 2002). The foremost activities of logistics service reliability capability include shipping of raw materials, distribution, warehousing, and quick deliveries of end-products to consumers. Therefore, organizations that intent to achieve better performance emphasize on the logistic service reliability capability of the organization. Logistics service reliability capability enables the logistics firms to generate and set out resources to satisfy their customers and in so doing enhance service performance (Lai, 2004). There are a number of attributes that define logistic service reliability capability within the firms, which may differ among across several organizations. The 
Journal of Business Management and Economic Research (JOBMER), vol.3, issue.9, pp.34-46

widely reported attributes of logistic service reliability capabilities include: firm reviews of service provision, client services quality scores, follow ups on service delivered, reverse logistic operations, speed of service delivery and logistic solutions, among others (Yang et al., 2016; Fernandes et al., 2018).

Firms intending to improve their overall performance. Therefore, need to emphasize the role of individual attribute and how they affect firm performance. However, there are currently few studies that have looked at the influence of each of the attributes singly or in combination on the overall firm performance. Therefore, the aim of this study was to evaluate influence of the attribute of Logistic service reliability capability on performance of manufacturing firms in Kenya, furthermore, test the following hypothesis: H01: There is an association between attribute of firms' logistic service reliability capability and firm performance

This study used the resource-based view which asserts that firms can gain and sustain competitive advantages which results to superior performance by developing and positioning valuable resources and capabilities or through acquiring and controlling the resources (Barney, 2001; Schroeder et al., 2002; Kraaijenbrink et al., 2010). In the context of RBV, organizations are viewed on how their assets, systems and capabilities are used in creating value. In most cases, the firms that gain advantage are those capable of accumulating resources and capabilities that are rare, valuable, non-substitutable and difficult to imitate. Capabilities of the firms take diverse forms such as innovation, organizational learning, and stakeholder integration (Siguaw et al., 2006). Accordingly, the focus has been on those capabilities and resources contained within the organization. Nevertheless, a firm's resources extending beyond their boundaries, is also capable of creating a competitive advantage and should also be considered. There is a relatively large literature in logistics service reliability capability considering the realm of RBV. Therefore RBV, can present a theoretical foundation for this study to examine the relationships between logistic service reliability capability and firm performance. 


\section{Conceptual Model of the study}

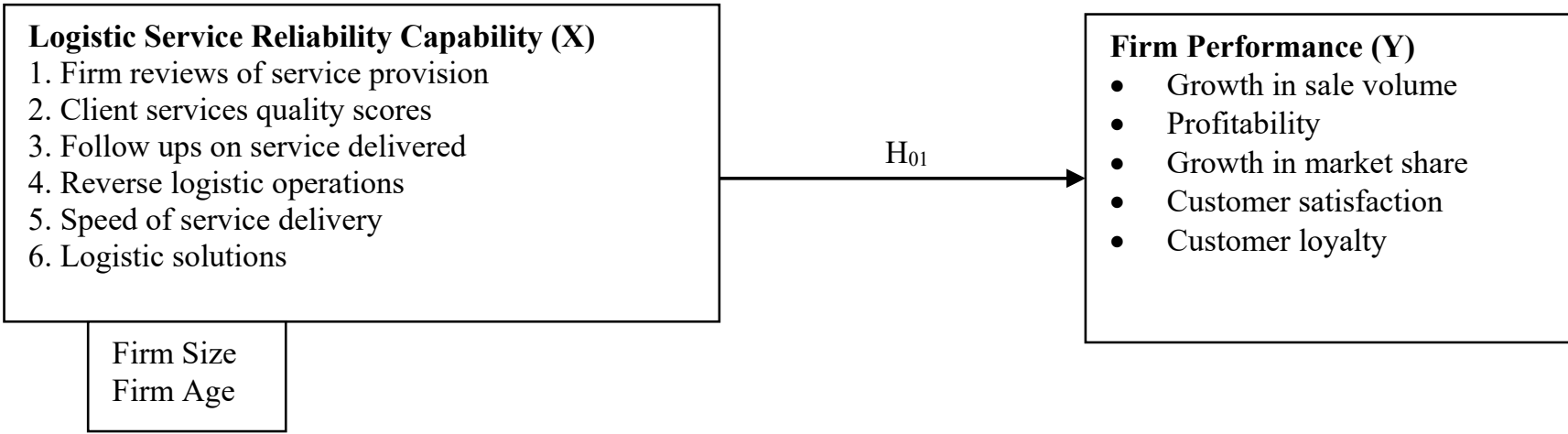

Control Variables

Figure 1: Conceptual Framework

\section{Methodology}

This study used positivism approach, which sought to use existing theory to deduce and formulate variables. The study was conducted using explanatory research design of a cross sectional nature. Explanatory research design analyzed the cause-effect relationship between two or more variables (Rahi, 2017). Hence the design was appropriate to the study because the research sought to establish a cause-effect relationship on the two constraints which is Logistic service reliability capability and firm performance. The target population was 750 manufacturing firms registered with Kenya Association of Manufacturers (KAM, 2018). The unit of analysis were purchasing and logistic managers of each firm which resulted to a sample size of 442 respondents. Stratified sampling combined with simple random sampling technique was used to select sample size. Structured questionnaires were used to collect data for dependent and independent variables, where each item was subjected to Five-point Likert scale ranging from Strongly Disagree (SD) to Strongly Agree (SA).

The dependent variable was firm performance measured using subjective measures of sales volume, profits, market share, customer satisfaction, customer loyalty and new products over the past three years as described in previous research studies (Farris et al., 2010; Santos \& Brito, 2012; Hill \& Alexander, 2017). The independent variable was logistic service reliability capability was measured based on literature from previously published method (Fernandes et al., 2018). To reduce the effects of confounding variables, the study included two control variables vis: firm size and firm age. 
Journal of Business Management and Economic Research (JOBMER), vol.3, issue.9, pp.34-46

The reliability of the research instrument was tested using the internal consistency technique by employing Cronbach Alpha value of 0.7. Internal and external validity was assessed to establish whether the research instrument truly measures what it is intended to (Patino \& Ferreira, 2018). Descriptive statistics used were the mean and standard deviation; inferential statistics was Pearson correlation coefficient to test the relationship and strength between the variables. Multiple regression models were used to test the hypotheses.

\section{Results}

\subsection{Characteristics of the Respondents}

The overall results of the socio-demographic background of the respondents are presented in Table 1. There were a higher proportion of the males compared with females suggesting more male employees in the firms. Most of the employees $(45.7 \%, n=202)$ were aged 36 to 55 years followed by 26-35 years. The least but not last is $21.3 \%$ (94) are above 18 to 32 years; lastly, 1.4\% (6) is above 63 years. In terms of educational status, 43.9\% attained Bachelor degree, 27.9\% Master degree, 18.3\% Diploma, 3.6\% (16) of the respondents have Certificate level of education. Majority of firms employed between 50 and 249 employees (46.4\%) followed by $>250$ employees $(24.7 \%)$ while $5 \%$ had less than 10 employees. Finally, overall age of the firm indicated that most had been operational operation from 10 to 30 years followed by those operating between $51-70$ years. $26.2 \%$ had operated for a period ranging from 51 to 70 years while $3.6 \%$ (16) were in operation for less than 10 years.

Table 1. Socio-Demographic Information $(n=442)$

\begin{tabular}{llcc}
\hline Socio-demographic attributes $(\mathrm{n}=442)$ & Variable attributes & Frequency & Percent \\
\hline Gender & Male & 235 & 53.2 \\
& Female & 207 & 46.8 \\
& $18-25$ years & 94 & 21.3 \\
& $26-35$ years & 140 & 31.7 \\
& $36-55$ years & 202 & 45.7 \\
& $<55$ years & 6 & 1.4 \\
Level of Education & Secondary school & 5 & 1.1 \\
& College Certificate & 16 & 3.6 \\
& College Diploma & 81 & 18.3 \\
& Bachelor degree & 194 & 43.9 \\
& Master degree & 123 & 27.8 \\
& PhD degree & 23 & 5.2 \\
\hline
\end{tabular}


Journal of Business Management and Economic Research (JOBMER), vol.3, issue.9, pp.34-46

\begin{tabular}{llcc}
\hline No. of Employees & $1-10$ & 22 & 5.0 \\
& $11-49$ & 106 & 24.0 \\
& $50-249$ & 205 & 46.4 \\
Firm Age & $>250$ & 109 & 24.7 \\
& $<10$ years & 16 & 3.6 \\
& $10-30$ years & 136 & 30.8 \\
& $31-50$ years & 85 & 19.2 \\
& $51-70$ years & 116 & 26.2 \\
& $>70$ years & 89 & 20.1 \\
\hline
\end{tabular}

\subsection{Reliability of Research Instruments}

The alpha coefficient results of the reliability tests (Table 2) show that follow ups on service delivered yielded the highest reliability ( $\alpha=0.945)$, followed by Speed of service delivery $(\alpha=0.888$ ), client services quality scores $(\alpha=0.812)$, firm reviews of service provision $(\alpha=0.802)$, reverse logistic operations $(\alpha=0.798)$, and finally, firm performance had a reliability score of $(\alpha=0.752)$. Reliability coefficients above 0.7 are considered acceptable and thus in the current study they were all good.

Table 2. Reliability of the attributes of the variables during the Study

\begin{tabular}{|c|c|c|}
\hline Variable & Cronbach's Alpha & Remark \\
\hline 1. Firm reviews of service provision $\left(\mathrm{x}_{1}\right)$ & 0.802 & Reliable \\
\hline 2. Client services quality scores $\left(\mathrm{x}_{2}\right)$ & 0.812 & Reliable \\
\hline 3. Follow ups on service delivered $\left(\mathrm{x}_{3}\right)$ & 0.956 & Reliable \\
\hline 4. Reverse logistic operations $\left(\mathrm{x}_{4}\right)$ & 0.798 & Reliable \\
\hline 5. Speed of service delivery $\left(x_{5}\right)$ & 0.888 & Reliable \\
\hline 6. Logistic solutions $\left(\mathrm{x}_{6}\right)$ & 0.774 & Reliable \\
\hline 7. Firm Performance & 0.752 & Reliable \\
\hline
\end{tabular}

\subsection{Firm Performance}

The dependent variable for this study was firm performance. The metric score for the firm performance is shown in Table 4. Based on five attributes of performance, the overall mean of 4.34/5.00 indicated a good firm performance. Among the attributes, Growth in market share, Customer satisfaction and Profitability were the greatest contributors to firm performance. 
Journal of Business Management and Economic Research (JOBMER), vol.3, issue.9, pp.34-46

Table 3. Metrics and Score of Attributes for the Firm Performance

\begin{tabular}{llll}
\hline Firm performance & Mean $(\mathrm{x} / 5.0)$ & SD & Rank $(\%)$ \\
\hline Growth in sale volume & 4.18 & 0.28 & 83.67 \\
Profitability & 4.27 & 0.29 & 85.34 \\
Growth in market share & 4.47 & 0.32 & 89.37 \\
Customer satisfaction & 4.44 & 0.33 & 88.73 \\
Customer loyalty & 4.17 & 0.24 & 83.30 \\
Total & $\mathbf{4 . 3 4}$ & $\mathbf{0 . 2 9}$ & $\mathbf{8 6 . 7 8}$ \\
\hline
\end{tabular}

\subsection{Logistic Service Reliability Capability}

Metric scores and ranks of the attributes of logistic service reliability capability are shown in Table 4. The overall score of the logistic service reliability capability is high (3.785/5.00) among the sampled firms. Metrics of logistic service reliability that elicited highest score was firm reviews of service provision (Mean $=4.07 \pm 0.21$ ), followed by follow ups on service delivered (Mean $=3.94 \pm 0.21$ ), reverse logistic operations $($ Mean $=3.91 \pm 0.17$ ). Meanwhile other attributes of logistic service reliability capabilities ranked lower including Logistic solutions (Mean $=3.85 \pm 0.17$ ), client services quality scores (Mean $=3.71 \pm 0.51$ ). The speed of service delivery was ranked the lowest in score among the sampled firms (Mean $=2.32 \pm 0.14$ ).

Table 4. Metrics and Score of Attribute of Logistic Service Reliability Capability

\begin{tabular}{|c|c|c|c|}
\hline Logistic Service Reliability capability $\uparrow$ & Mean $(x / 5.0)$ & SD & Rank (\%) \\
\hline 1. Firm reviews of service provision $\left(\mathrm{x}_{1}\right)$ & 4.07 & 0.21 & 81.49 \\
\hline 2. Client services quality scores $\left(\mathrm{x}_{2}\right)$ & 3.71 & 0.15 & 74.20 \\
\hline 3. Follow ups on service delivered $\left(x_{3}\right)$ & 3.94 & 0.17 & 78.87 \\
\hline 4. Reverse logistic operations $\left(\mathrm{x}_{4}\right)$ & 3.91 & 0.17 & 78.19 \\
\hline 5. Speed of service delivery $\left(x_{5}\right)$ & 3.23 & 0.18 & 64.62 \\
\hline 6. Logistic solutions $\left(\mathrm{x}_{6}\right)$ & 3.85 & 0.17 & 77.00 \\
\hline Total & 3.785 & 0.18 & 75.7 \\
\hline
\end{tabular}

$\uparrow$ Variables are described in Figure 1.

\subsection{Test for the Direct effects of Logistic Service Reliability Capability on Firm Performance}

The regression test was done for both the controls and the independent variables (direct effect). The hypotheses tested the effect of logistic service reliability capability on performance of manufacturing firms in Kenya. The results of the study variables were presented in Table 5. The results indicated that the predictors explained $64.2 \%$ of the variation change on firm performance (R-squared $=0.6421$, 
Journal of Business Management and Economic Research (JOBMER), vol.3, issue.9, pp.34-46

Multiple $\mathrm{R}=0.8013, P<0.05$ ). The findings also indicated that the coefficient of determination was significant $(F=129.9890, p$-value $=<.000)$. Accordingly, Speed of service delivery $(\beta=0.1918)$, Logistic solutions $(\beta=0.0 .1903)$ and Reverse logistic operations $(\beta=0.1804)$ were the most important attributes that significantly correlated with firm performance. While the least attribute that affected firm performance was Client services quality scores $(\beta=0.0826)$.

Table 5. Multiple Linear regression statistics showing the relationship between logistic Service Reliability Capability and firm performance in manufacturing firms in Kenya

\begin{tabular}{|c|c|c|c|c|c|}
\hline \multicolumn{2}{|l|}{ Regression Statistics } & & & & \\
\hline Multiple R & 0.8013 & & & & \\
\hline R Square & 0.6421 & & & & \\
\hline Standard Error & 0.3377 & & & & \\
\hline Observations & 442 & & & & \\
\hline Durbin-Watson & 1.896 & & & & \\
\hline ANOVA & $d f$ & SS & MS & $F$ & P-value \\
\hline Regression & 5 & 74.1407 & 14.8281 & 129.9890 & 0.0000 \\
\hline Residual & 226 & 25.7803 & 0.1141 & & \\
\hline \multirow[t]{2}{*}{ Total } & 231 & 99.9210 & & & \\
\hline & Coefficients & Standard Error & tStat & P-value & Beta \\
\hline Intercept & 0.4275 & 0.0022 & 23.3280 & 0.0000 & \\
\hline 1. Firm reviews of service provision & 0.0828 & 0.0288 & 2.8711 & 0.0045 & 0.1023 \\
\hline 2. Client services quality scores (x2) & 0.0750 & 0.0336 & 2.2339 & 0.0265 & 0.0826 \\
\hline 3. Follow ups on service delivered $(x 3)$ & 0.0880 & 0.0277 & 3.1720 & 0.0017 & 0.1087 \\
\hline 4. Reverse logistic operations $(x 4)$ & 0.1460 & 0.0252 & 5.7886 & 0.0000 & 0.1804 \\
\hline 5. Speed of service delivery (x5) & 0.1553 & 0.0264 & 5.8796 & 0.0000 & 0.1918 \\
\hline 6. Logistic solutions $\left(\mathrm{x}_{6}\right)$ & 0.1660 & 0.0252 & 5.7886 & 0.0000 & 0.1903 \\
\hline \multicolumn{6}{|c|}{ Dependent Variable: Firm performance } \\
\hline \multicolumn{6}{|l|}{ Collinearity statistics } \\
\hline Tolerance & 1.000 & & & & \\
\hline VIF & 1.000 & & & & \\
\hline
\end{tabular}

$\uparrow$ Variables are described in Figure 1.

\section{Discussion}

\subsection{Firm Performance}

The dependent variable for this study was firm performance. The metric score for the firm performance is shown in Table 4. Based on five attributes of performance, the overall mean of 4.34/5.00 indicated a good firm performance. Among the attributes, Growth in market share, Customer satisfaction and Profitability were the greatest contributors to firm performance. 
Journal of Business Management and Economic Research (JOBMER), vol.3, issue.9, pp.34-46

Logistic Service reliability capability is characterized by the manufacturing firms' ability to create and deploy resources that would satisfy the logistic needs of their customers (Lai, 2004). The study therefore sought to establish the attributes that contribute to the service reliability capacity among manufacturing firms. Metric scores and ranks of the attributes of logistic service reliability capability are shown in Table 4. Metrics of logistic service reliability that elicited highest score was firm reviews of service provision (Mean $=4.07 \pm 0.21$ ), followed by follow ups on service delivered (Mean $=3.94 \pm$ 0.21 ), reverse logistic operations (Mean $=3.91 \pm 0.17$ ). Meanwhile other attributes of logistic service reliability capabilities ranked lower including Logistic solutions (Mean $=3.85 \pm 0.17$ ), client services quality scores $($ Mean $=3.71 \pm 0.51)$. The speed of service delivery was ranked the lowest in score among the sampled firms (Mean $=2.32 \pm 0.14$ ).

The sampled manufacturing firms in Kenya engage in the identification of problem areas in the firm that have led to client loss due to poor services provision, timely delivery of the products and services. Once the weaknesses are inherent in the firm, the firm takes an affirmative action of identifying and the necessary action is taken with emphasis on meeting client specifications. The reason for this is that clients are the most important factor for the firms. Moreover, the firms search for prior solutions for logistic problems enables the manufacturing firms to identify problem before they actually occur by being pro-active. Besides, reverse logistics operations are developed by the firm. The implication is that the firms are more responsive to customers and are likely to exhibit higher productivity because of meeting customer requirements on time.

Therefore, there is a statistically significant effect of logistic service reliability capability on firm performance. The findings concur with those of Yang et al., (2009) who observed that logistic service reliability capability is a core competence in leading to superior performance and creating customer value. Similarly, both Lu and Yang's (2010) and Yang's (2012) were unequivocal that logistic service reliability capability facilitates the coordination of activities and makes use of resources for managing and integrating processes within supply chains which augment customer service performance. Logistic service reliability capabilities have also been previously equated to cost, quality, flexibility, delivery, and innovation, as drivers of superior firm performance (Wang et al., 2015). The findings are also consistent with that of (Yang et al., 2009) which established that liner manufacturing firms' logistics service reliability capability can significantly lead to superior performance. In this study the attributes of logistic service reliability capability had a positive influence on firm performance were speed of service delivery, logistic solutions and reverse logistic operations which concurs with studies elsewhere (Fernandes et al., 2018). While the least attribute that affected firm performance was service 
Journal of Business Management and Economic Research (JOBMER), vol.3, issue.9, pp.34-46

provision, follow up on service delivered and client services quality scores suggesting that clients were not satisfied with the quality of services provided by these firms.

\section{Conclusion}

The rapid growth of the manufacturing industry in the whole world has boosted the demand for logistics services in order to cater to the movement of manufactured products from the point of origin to ultimate customer/user. This study tested a null hypothesis that there is no significant empirical relationship between attribute of Logistic service reliability capability and firm performance $\left(\mathrm{H}_{01}\right)$. The study provided evidence that speed of service delivery, logistic solutions and reverse logistic operations were the most important attribute that significantly explained firm performance. However, firm appeared to concentrate on other attributes such as service provision and follow up on service delivered and client service on quality scores which did not have strong effects on the performance.

\section{Suggestions}

For a long-term development, manufacturing firms should clearly delineate the most important attribute of Logistic service reliability capability and enhance them, while improving those that are not highly rated in the firm. In highly competitive firm environment where differentiation is the key competitive advantage, strong attribute associated with logistic service reliability capability is required to enhance the overall information flow within the supply chain.

The study findings established that better performing manufacturing firms must employ certain attribute of logistic service reliability capability. Therefore, there is need for manufacturing firms to adopt logistic service reliability capabilities that will positively influence performance. Manufacturing firms should invest only on those service capabilities that can create a competitive differentiation strategy for sustainable performance such as improving the service provision, follow up on service delivered and enhancing client service quality scores in order to satisfy the customer requirements. Moreover, managers must not only develop unique capabilities internally, but they must recognize the combined effects of supply chain practices that can generate a total impact on operational capabilities both at upstream and downstream of the supply chain. 
Journal of Business Management and Economic Research (JOBMER), vol.3, issue.9, pp.34-46

In emphasizing the importance of Resource Based view theory, firms are should evaluate potential factors that can be deployed to confer to firm performance including using available resources to add value to their products. It also encourages firms to produce their products in a way that they cannot be imitated or substituted to increase their performance. Therefore, the contribution of this theory is validated by this study since it encourages the management of manufacturing firms to invest in improving Logistic service reliability capability to develop, nurture and maintain key resources and competencies in order to improve the performance of the firm.

In any research, not all existing constructs from literature could be included in the model. For the purpose of this study, only few significant constructs are selected in regards to the issues highlighted. Thus, future researchers are invited to integrate other relevant and significant constructs in the present model in order to reveal a deeper understanding of determinants affecting the performance of manufacturing firms.

8. Funding: This research received no external funding.

9. Acknowledgement: I am grateful to Prof. Charles Lagat, Dr. Joel Chepkwony and Dr. Jane Sang for their professional guidance, inspiration, patience, support and advice throughout the entire process of developing this research paper.

10. Conflict of Interest: The author declares no conflict of interest.

\section{References}

Arena, M., Azzone, G., Bengo, I. (2015). Performance measurement for social enterprises. VOLUNTAS: International Journal of Voluntary and Nonprofit Organizations. 26, 649-672.

Barney, J.B. (2001). Resource-based theories of competitive advantage: A ten-year retrospective on the resource-based view. Journal of management. 27, 643-650.

Chapman, R.L., Soosay, C., Kandampully, J. (2002). Innovation in logistic services and the new business model: a conceptual framework. Managing Service Quality: An International Journal.

Chiang, F.F., Birtch, T.A. (2012). The performance implications of financial and non-financial rewards: an Asian Nordic comparison. Journal of Management Studies. 49, 538-570.

Durst, S., Evangelista, P. (2018). Logistics knowledge management: state of the art and future perspectives. Knowledge Management Research \& Practice. 16, 427-434. 
Journal of Business Management and Economic Research (JOBMER), vol.3, issue.9, pp.34-46

Farris, P.W., Bendle, N., Pfeifer, P., Reibstein, D. (2010). Marketing metrics: The definitive guide to measuring marketing performance. Pearson Education.

Fernandes, D.W., Moori, R.G., Filho, V.A.V. (2018). Logistic service quality as a mediator between logistics capabilities and customer satisfaction. Revista de Gestão. 25, 358-372.

Franceschini, F., Rafele, C. (2000). Quality evaluation in logistic services. International Journal of Agile Management Systems. 2, 49-54.

Hill, N., Alexander, J. (2017). The handbook of customer satisfaction and loyalty measurement. Routledge.

Ibrahim, S., Lloyd, C. (2011). The association between non-financial performance measures in executive compensation contracts and earnings management. Journal of Accounting and Public Policy. 30, 256-274.

Kharatyan, D., Nunes, A., Lopes, J. (2016). Financial ratios and indicators that determine return on equity. XVII-Encuentro AECA.

Kraaijenbrink, J., Spender, J.-C., Groen, A.J. (2010). The resource-based view: a review and assessment of its critiques. Journal of management. 36, 349-372.

Kristjansdottir, K., Shafiee, S., Bonev, M., Hvam, L., Bennick, M.H., Andersen, C.S. (2016). Improved Performance and Quality of Configurators by Receiving Real-Time Information from Suppliers, Configuration Workshop.

Lai, K.-h. (2004). Service capability and performance of logistics service providers. Transportation Research Part E: Logistics and Transportation Review. 40, 385-399.

Liu, L., Luo, D. (2012). Effects of logistics capabilities on performance in manufacturing firms. Contemporary Logistics. 9, 8-14.

Najafizadeh, A., Kazemi, F. (2019). The Impact of Reverse Logistics Capabilities on Firm Performance with Mediating Role of Business Strategy. Journal of System Management. 225-240.

Owens, I., Wilson, T., Abell, A. (2019). Information and Business Performance: A Study of Information Systems and Services in High-Performing Companies. Walter de Gruyter GmbH \& Co KG.

Patino, C.M., Ferreira, J.C. (2018). Internal and external validity: can you apply research study results to your patients? Jornal Brasileiro de Pneumologia. 44, 183-183.

Rahi, S. (2017). Research design and methods: A systematic review of research paradigms, sampling issues and instruments development. International Journal of Economics \& Management Sciences. 6, 1-5.

Santos, J.B., Brito, L.A.L. (2012). Toward a subjective measurement model for firm performance. BARBrazilian Administration Review. 9, 95-117.

Schönsleben, P. (2018). Integral logistics management: operations and supply chain management within and across companies. CRC Press.

Schroeder, R.G., Bates, K.A., Junttila, M.A. (2002). A resource-based view of manufacturing strategy and the relationship to manufacturing performance. Strategic management journal. 23, 105-117.

Siguaw, J.A., Simpson, P.M., Enz, C.A. (2006). Conceptualizing innovation orientation: A framework for study and integration of innovation research. Journal of product innovation management. 23, 556-574.

Torres, R., Sidorova, A., Jones, M.C. (2018). Enabling firm performance through business intelligence and analytics: A dynamic capabilities perspective. Information \& Management. 55, 822-839. 
Journal of Business Management and Economic Research (JOBMER), vol.3, issue.9, pp.34-46

Wang, Y., Wallace, S.W., Shen, B., Choi, T.-M. (2015). Service supply chain management: A review of operational models. European Journal of Operational Research. 247, 685-698.

Yang, C.-C., Marlow, P.B., Lu, C.-S. (2009). Assessing resources, logistics service capabilities, innovation capabilities and the performance of container shipping services in Taiwan. International Journal of Production Economics. 122, 4-20.

Yang, S., Liu, J., Wang, K., Miao, Y. (2016). An uncertain QFD approach for the strategic management of logistics services. Mathematical Problems in Engineering. 2016.

Zijm, H., Klumpp, M., Heragu, S., Regattieri, A. (2019). Operations, Logistics and Supply Chain Management: Definitions and Objectives, Operations, Logistics and Supply Chain Management. Springer, pp. 27-42. 